\title{
Prune belly syndrome: a case of early prenatal diagnosis
}

\section{Suvidhi Kamra ${ }^{1}$, Unmesh Santpur ${ }^{1 *}$, Nidhi Puri², Neetu Pippet ${ }^{2}$}

\author{
${ }^{1}$ Department of Obstetrics and Gynecology, Maharishi Markandeshwar Institute of Medical Sciences and Research, \\ Mullana, Ambala, Haryana, India \\ ${ }^{2}$ Department of Anatomy, Maharishi Markandeshwar Institute of Medical Sciences and Research, Mullana, Ambala, \\ Haryana, India
}

Received: 18 January 2017

Accepted: 27 February 2017

\section{*Correspondence:}

Dr. Unmesh Santpur,

E-mail: santpurunmesh@rediffmail.com

Copyright: (C) the author(s), publisher and licensee Medip Academy. This is an open-access article distributed under the terms of the Creative Commons Attribution Non-Commercial License, which permits unrestricted non-commercial use, distribution, and reproduction in any medium, provided the original work is properly cited.

\section{ABSTRACT}

Prune belly syndrome is a rare congenital disorder typically characterized by a triad of malformation of the urogenital tract, defect of abdominal wall musculature, and cryptorchidism. The condition is generally incompatible with life as infants born with this syndrome are either stillborn or die within the first few weeks of life. The present case is of a fetus presenting with prune bell syndrome, detected in first trimester of pregnancy.

Keywords: Abdominal wall musculature, Abortus, Cryptoorchidism, Megalourethra, Prune belly syndrome, Ultrasound

\section{INTRODUCTION}

Frequent use of antenatal ultrasound has enabled us to detect various fetal anomalies at earlier gestations, thus providing a new arena for effective management and further investigation of fetal anomalies. We present a case of prune belly syndrome detected as early as 11 weeks of gestation, which according to us is a very early detection. Prune belly syndrome characteristically consists of a spectrum of anomalies mainly resulting from early structural obstruction of distal urinary tract.

Prune Belly syndrome (PBS) is a rare congenital anomaly the etiology of which is not known. It is synonymous with Abdominal muscle deficiency syndrome, Osler-Parker Syndrome, Eagle Barret Syndrome and Mesenchymal dysplasia syndrome.

It is characterized by a classical triad of congenital absence of abdominal wall muscles, malformation of the urogenital tract and cryptorchidism. The characteristic 'Prune-like' appearance of the anterior abdomen wall is the diagnostic feature. However, renal function is the most important factor that determines the survival. The other associated anomalies are pulmonary hypoplasia, club foot, potter's facies and hip dislocation. The pathogenesis of PBS is still an unsettled controversy. The estimated incidence is 1 in 35,000-50,000 live births and occurs almost exclusively in males (M: F=20:1). ${ }^{1}$ Higher incidence has been reported in twin pregnancies as well as children born to younger mothers. ${ }^{2}$

\section{CASE REPORT}

A $23 \mathrm{yr}$ old primigravida, with 12 weeks gestation, presented to antenatal clinic for routine antenatal checkup. There was no history of any drug intake, no consanguineous marriage and no family history of any congenital malformation. Routine antenatal checkup was done.

Ultrasonography showed live intrauterine pregnancy of 11 weeks' gestation with enlarged cystic area of size $2 \times 1.6 \mathrm{~cm}$ in abdomen (Figure 1). Crown rump length (CRL) was $4.7 \mathrm{~mm}$ and other fetal biometric values were 
appropriate for the gestational age. Based on USG, a provisional diagnosis of Prune belly syndrome was made.

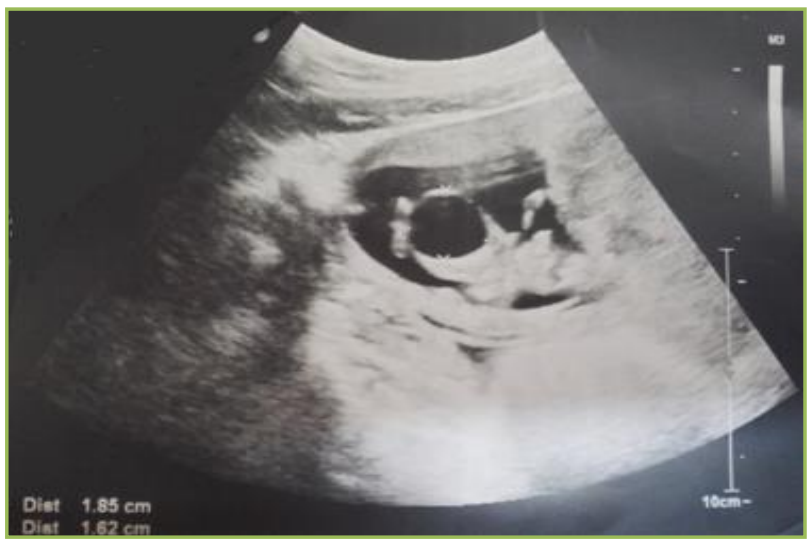

Figure 1: Antenatal USG.

Prognosis of fetus as well as long term complications were explained to the patient and her husband. Pregnancy was terminated on couple's request. Detailed autopsy examination was done in the department of Anatomy and diagnosis of Prune Belly syndrome was made.

\section{Gross examination}

A male fetus of 11 weeks' gestation in which anterior abdominal wall was not developed, urinary bladder was exposed and ureters were enlarged.

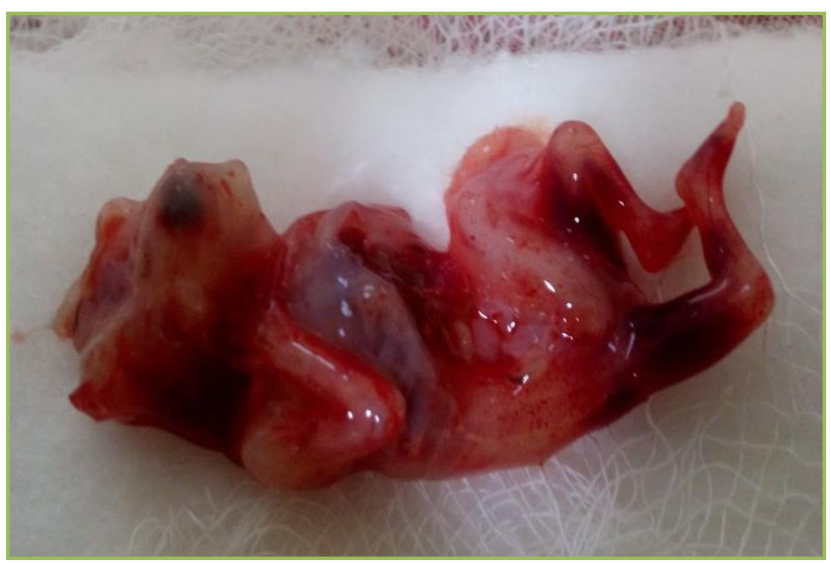

Figure 2: Gross examination of fresh abortus specimen showing absence of anterior abdominal wall musculature.

Kidneys however were normal on gross examination. Well-developed lungs, heart, liver and GIT were seen. Physiological hernia was not evident and bowel was seen within the abdominal cavity (Figure 2, Figure 3 and Figure 4).

\section{Histological examination}

On histological examination, abdominal wall showed predominant mesenchymal tissue while no muscle tissue was appreciated (Figure 5).

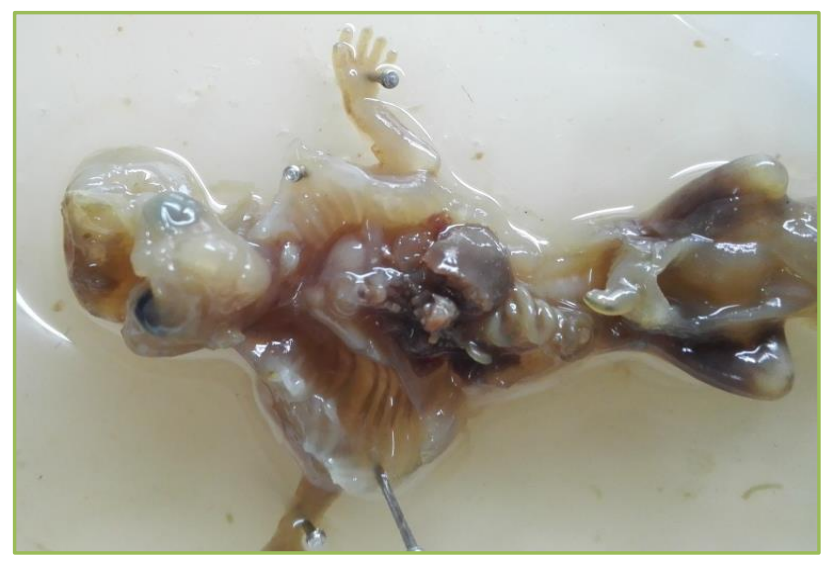

Figure 3: Fetus on dissection showing well developed heart, lungs, intestines, liver and kidneys.

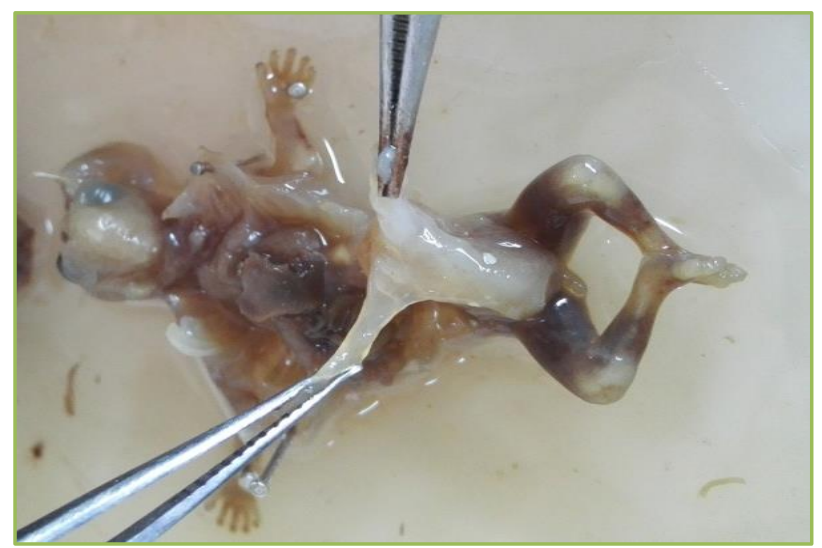

Figure 4: Fetus with exposed urinary bladder with dilated ureters.

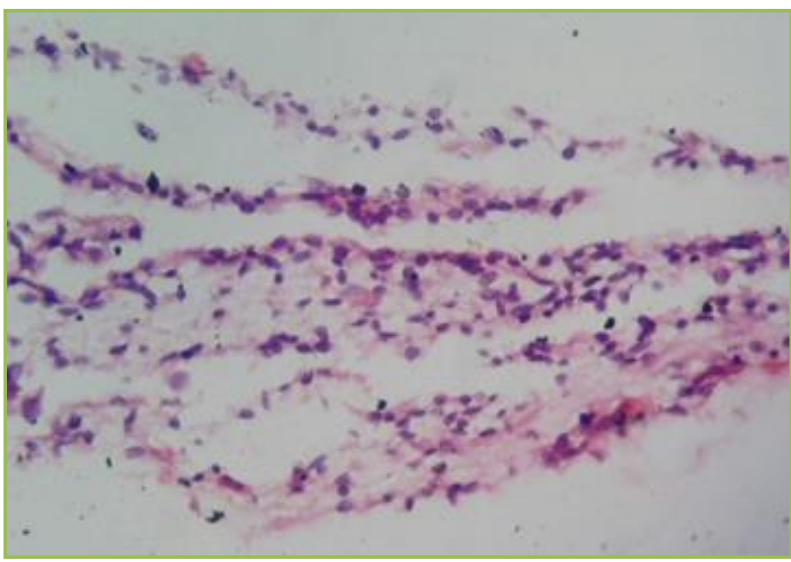

Figure 5: Section of anterior abdominal wall showing only connective tissue with no developing muscular tissue. 
Kidney parenchyma was well developed (Figure 6). Both ureters were patent and left ureter was comparatively more tortuous and dilated than right.

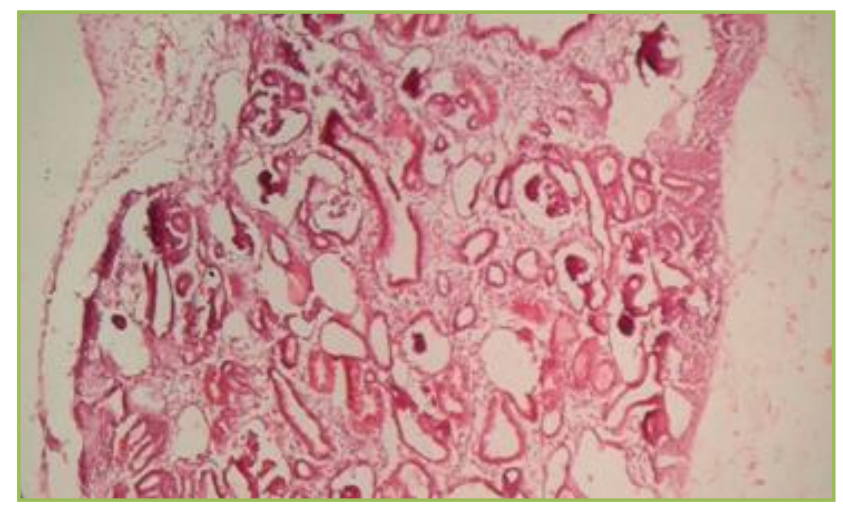

Figure 6: Section of kidney showing normal development.

Wall of urinary bladder was showing normal developing transitional epithelium and muscular tissue with no signs of inflammation or fibrosis (Figure 7).

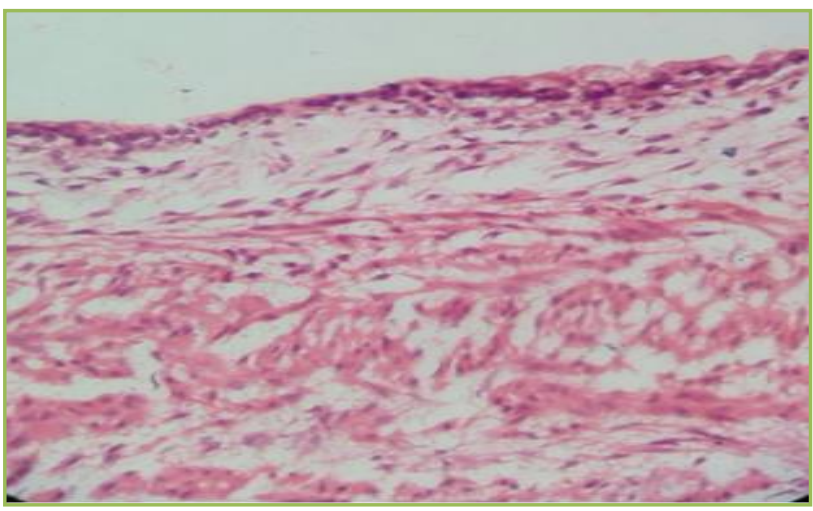

Figure7: Section of urinary bladder with transitional epithelium and developing musculature.

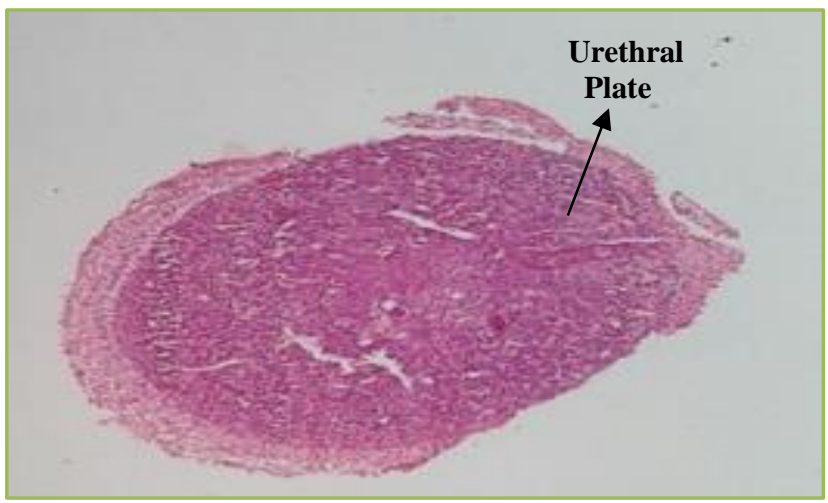

Figure 8: Section of penis urethral orifice not developed.

Transverse section of penis, developing penile tissue was observed but no patent urethral opening was seen within it (Figure 8). Other sections showed normal developing lung, liver and gut.

\section{DISCUSSION}

Prune belly syndrome (PBS) was first described in 1839 by Frolich. Osler gave the condition its name in 1901. A fully developed syndrome characterized by the classic triad is seen only in males. ${ }^{3}$ An incomplete one, called the female syndrome (Pseudo-prune belly syndrome) is rare and accounts for less than $3 \% .^{4,5}$

Accounting to Routh et al, various non-urological anomalies are seen associated with PBS accounting for cardiovascular in 25\%, gastrointestinal in $24 \%$, musculoskeletal in $23 \%$, and respiratory in $58 \%$ of their cases. Sepsis and especially urosepsis are found in $14 \%$ and $2 \%$ cases respectively. ${ }^{6}$ Though the exact etiology of PBS is not known, cases reported in families and siblings, suggest a genetic predisposition.

Recently two non-familial cases of PBS with deletion at chromosome $17 q 12$ involving HNF1 $\beta$ gene were reported, so it has been suggested that it could be the candidate gene for prune belly syndrome. ${ }^{1}$ However further genetic study is required to identify the genetic basis of the disease. Though the underlying primary molecular defect of PBS remains unclear, three main theories have been put forward to explain its pathogenesis:

- The mesodermal defect theory suggests that there is failure of differentiation of mesoderm between $6^{\text {th }}$ and $10^{\text {th }}$ weeks of gestation. This theory is able to explain genitourinary tract, testis and abdominal wall defects but fails to explain other associated factors. ${ }^{7}$

- According to the Yolk sac theory of Prune belly syndrome, during embryological period, the posterior urethra and bladder develop from a portion of allantois. In these cases, an abnormal amount of yolk sac is retained and could affect the abdominal wall development resulting in a prune like appearance. The allantoic diverticulum may be incorporated in the urinary tract and this forms the enlarged urachus. ${ }^{7}$ However this theory fails to explain the genitourinary tract involvement.

- Theory of prenatal obstruction of the urinary tract suggests pressure atrophy of the abdominal wall muscles secondary to distended bladder and ureters. This theory is able to explain the occurrence of nondescent of testis and bilateral cryptorchidism. ${ }^{8}$

Another theory that could possibly explain the pathogenesis of PBS suggests that urethral obstruction may be a functional rather than mechanical. Prostatic hypoplasia causes structural change in prostatic urethra during voiding like megalourethra. The obstructive process leads to high pressure voiding and reflux which may be responsible for change in ureteral location and the water hammer effect on the renal tissue leading to renal 
dysplasia. The over distended bladder prevents testicular descent and prevents the normal development of abdominal wall muscles. ${ }^{9}$

Prune Belly Syndrome (PBS) can be characterized by partial hypoplasia or complete absence of the anterior abdominal wall muscles where all three-muscle layer of abdomen get affected. The order of involvement from most to least involved is: transversus abdominis, rectus abdominis below the umbilicus, internal oblique, external oblique and rectus abdominis above the umbilicus. ${ }^{10}$ In both urinary bladder and ureters, the muscles become sparse and patchy and get replaced by collagen or fibrous tissue. ${ }^{11}$ In our case, autopsy examination revealed absence of well-developed anterior abdominal wall muscles. There was grossly dilated bladder with tortuous bilateral ureters.

Cryptorchidism however was not so evident owing to early gestation. The case was thus diagnosed as prune belly syndrome with the exclusion of other urinary tract anomalies. The prognosis of PBS is usually poor as a high percentage of patients are either stillborn or die during their initial hospitalization. Those who survive have variable urinary pathologies and many of them develop renal failure. Thus, despite all the advances in perinatal care, mortality in infancy or early childhood is a common outcome. The main prognostic factor seems to be the severity of renal pathology; however, urosepsis and respiratory failure are also of definitive importance. Although the condition is usually incompatible with life due to visceral abnormalities especially that of renal function, there are cases who survived into adult life after urinary tract repair and abdominal reconstruction surgery. ${ }^{12}$

Leeners et al suggested that intrauterine therapeutic options including in-utero placement of a vesicouterine shunt can be done to prevent the development of PBS in antenatally diagnosed cases. ${ }^{13}$ However, these procedures may not be readily available in resource limited settings.

\section{CONCLUSION}

The birth defects in newborn pose a great economical and emotional burden to the society as well as the couple involved. Prenatal diagnosis of anomalies like PBS is of great help especially in low-resource population. Careful examination of the products of conception (including the abortus as well as placenta) also holds utmost importance in this regard. Early detection of anomalies by ultrasound and autopsy of the abortus would also help to formulate the guidelines for management of the patient in her next pregnancy. This would improve the overall fetal outcome.

Funding: No funding sources

Conflict of interest: None declared

Ethical approval: Not required

\section{REFERENCES}

1. Vani A, Saritha S, Sangeetha K, Supriya G. Prune belly syndrome (sequenze): a case report. Int J Res Med Sci. 2013;1(2):148-52.

2. Druschel CM. A descriptive study of prune belly in New York State, 1983 to 1989. Archives of pediatrics and adolescent medicine. 1995;149(1):706.

3. YIP Felix, M Richard. Pediac Urology 3rd ed, Butterworth Heinemann;1997:618-20.

4. Aaronson IA, Cremin BJ. Prune belly syndrome in young females. Urologic Radiol. 1980;1(1):151-5.

5. Rabinowitz R, Schillinger JF. Prune belly syndrome in the female subject. J Urol. 1977 Sep;118(3):454-6.

6. Routh JC, Huang L, Retik AB, Nelson CP. Contemporary epidemiology and characterization of newborn males with prune belly syndrome. Urol. 2010;76(1):44-8.

7. Stephens FD, Gupta DE. Pathogenesis of the prune belly syndrome. J Urol. 1994;152:2328-31.

8. Greskovich FJ, Nyberg Jr LM. The prune belly syndrome: a review of its etiology, defects, treatment and prognosis. J Urol. 1988;140(4):707-12.

9. Franco I, Langenstroer P, Talavera F. Prune belly syndrome. E medicine from WebMD. 2006.

10. Eagle JF, Barrett GS. Congenital deficiency of abdominal musculature with associated genitourinary abnormalities: A syndrome report of nine cases. Pediatrics. 1950;6(5):721-36.

11. Palmer JM, Tesluk H. Ureteral pathology in the prune belly syndrome. J Urol.1974;111(5):701-7.

12. Woodhouse CR. Prospects for fertility in patients born with genitourinary anomalies. J Urol. 2001;165(6):2354-60.

13. Leeners B, Sauer I, Schefels J, Cotarelo CL, Funk A. Prune-belly syndrome: Therapeutic options including in utero placement of a vesicoamniotic shunt. Journal of clinical ultrasound. 2000;28(9):500-7.

Cite this article as: Kamra S, Santpur U, Puri N, Pippet N. Prune belly syndrome: A case of early prenatal diagnosis. Int J Reprod Contracept Obstet Gynecol 2017;6:1652-5. 